Article

\title{
Planning for a Low Carbon Future? Comparing Heat Pumps and Cogeneration as the Energy System Options for a New Residential Area
}

\author{
Jukka Heinonen ${ }^{1,2, *}$, Jani Laine ${ }^{2, \dagger}$, Karoliina Pluuman ${ }^{2,3, \dagger}$, Eeva-Sofia Säynäjoki ${ }^{2}$, \\ Risto Soukka ${ }^{3}$ and Seppo Junnila ${ }^{2}$
}

1 Faculty of Civil and Environmental Engineering, University of Iceland, Hjardarhagi 2-6, 107 Reykjavik, Iceland

2 Department of Real Estate, Planning and Geoinformatics, Aalto University, P.O. Box 15800, 00076 Aalto, Finland; E-Mails: jani.laine@aalto.fi (J.L.); karoliina.pluuman@lut.fi (K.P.); eeva.saynajoki@aalto.fi (E.-S.S.); seppo.junnila@aalto.fi (S.J.)

3 School of Energy Systems, Lappeenranta University of Technology, PL 20, 53851 Lappeenranta, Finland; E-Mail: risto.soukka@lut.fi

$\dagger$ These authors contributed equally to this work.

* Author to whom correspondence should be addressed; E-Mail: heinonen@hi.is;

Tel.: +354-823-0064.

Academic Editor: Enrico Sciubba

Received: 6 March 2015 / Accepted: 20 August 2015 / Published: 27 August 2015

\begin{abstract}
The purpose of this paper is to compare, from an urban planning perspective, the choice between combined heat and power (CHP) and a ground-source heat pump (HP) as the energy systems of a new residential area in the light of the uncertainty related to the assessments. There has been a strong push globally for CHP due to its climate mitigation potential compared to separate production, and consequently it is often prioritized in planning without questioning. However, the uncertainties in assessing the emissions from CHP and alternative options in a certain planning situation make it very difficult to give robust decision guidelines. In addition, even the order of magnitude of the climate impact of a certain plan is actually difficult to assess robustly. With a case study of the new residential development of Härmälänranta in Tampere, Finland, we show how strongly the uncertainties related to (1) utilizing average or marginal electricity as the reference; (2) assigning emissions intensities for the production; and (3) allocating the emissions from CHP to heat and electricity affect
\end{abstract}


the results and lead to varying decision guidelines. We also depict how a rather rarely utilized method in assigning the emissions from CHP is the most robust for planning support.

Keywords: urban planning; greenhouse gas; GHG; energy system; heat pump; cogeneration; combined heat and power; CHP; district heat; marginal production

\section{Introduction}

According to the IPCC (Intergovernmental Panel on Climate Change) (2011), energy production from fossil fuels is responsible for over 55\% of the world's greenhouse gas (GHG) emissions [1]. The IEA (The International Energy Agency) (2008a) estimates that the share of energy consumed in cities accounts for over $70 \%$ of these emissions [2]. Moreover, cities form an even more important arena for climate change mitigation efforts given that city administrations have a unique ability to communicate with the public and respond to public demands quickly and efficiently and thus to bring about meaningful changes at a local level in response to global issues such as climate change [3].

Urban planning is a key channel for the municipal energy efficiency and climate action [4]. Compact urban form is predominantly seen as a prerequisite for urban environmental sustainability $[5,6]$ further increasing the importance of the development of urban settlements. Consequently, further urbanization and densification of existing urban structures have become key planning strategies because of their connection to reduced energy requirements for housing and transportation (e.g., [7,8]). The greater density of urban structures also enables combined heat and power (CHP) production and district heating $(\mathrm{DH})$, which are seen as promising means to reduce the energy systems related GHGs around the globe $[9,10]$. CHP can potentially decrease the fuel requirements by one third compared to separate production with an equal fuel-mix [11-13].

The global role of CHP is also expected to increase radically in the near future. In 2007, the G8 countries unanimously urged a radical increase in global CHP production [9] and the process is being implemented. For example, the CHP share is estimated to increase from the current 2015 levels of below $20 \%$ in China and in Germany to $30 \%$ in 2030 , to $18 \%$ from the current $13 \%$ in the US, and to $16 \%$ from the current $9 \%$ in France [9]. Germany has even set itself an official technology penetration target to increase the share of power production by CHP to $25 \%$ in 2020 [14].

However, the environmental justification for the dominance of densification and CHP-centered policies has also been questioned, and alternative approaches to urban sustainability suggested [15-18]. Therefore, comparing the environmental benefits of CHP and other energy system options is becoming a topical issue in urban planning.

Actually, under the typical conditions of local DH networks in CHP environments and wider scale electricity grids, a number of significant uncertainties hinder verifying the environmental rationale of the decisions on energy systems and comparisons between CHP and other options. First, the choice of utilizing average or marginal technology in an assessment for electricity is often not clear, while the impact on the assessment results can be huge (e.g., [19]) as marginal technologies tend to be the most polluting. Marginal technology refers to the last generator that produces electricity to the network and the marginal electricity mix is defined as the last set of power plants that provides electricity to the 
network [20]. It has also been suggested that marginal production should refer to a number of technologies instead of one $[21,22]$.

Secondly, a life cycle perspective to the emissions intensities of different energy options adds an important angle to the complexity due to the high variation in the published results (e.g., [23]). The uncertainties found in life cycle assessments (LCA) of energy production are actually one of the main problems in LCAs [24]. Furthermore, the two basic LCA approaches, attributional LCA (ALCA) and consequential LCA (CLCA), can lead to very different outcomes, but it can be very unclear which approach to utilize. The selection of approach also relates to the marginal $v s$. average production question. ALCA can be defined as a method to describe a system as it is and CLCA as a method to assess how a system will change due a certain decision (e.g., [25]). It has been said that in ALCA average technologies should be utilized, whereas CLCA refers to the situation of marginal technologies (e.g., [25,26]). Plevin et al. (2013) go as far as to state that ALCA should not be used when policy guidelines are searched for or the LCA results facilitate decision making [26], but there is no consensus on the question among the scientific community. The boundaries used define both marginal and average technologies and this also causes variation in studies together with the use of different LCA approaches.

Nevertheless, defining when a marginal change in demand actually occurs in the context of urban development is a complex task. As to residential energy use, new residential developments increase the demand from a local perspective, but when the boundary is extended to cover the whole system the local increase appears predominantly only as a change in the geography of demand as households move to the new location. However, any change in the geography of demand, change in temporal demand or change in quantity will have an impact on marginal power production dynamics on a system level. Since the environmental intentions in urban planning are no longer limited to the local environmental quality but include the contribution to global issues such as climate change, local optimization does not necessarily serve far-reaching planning purposes. While one option may seem to be preferable within a restricted area, from a wider perspective the situation can appear as very different. Therefore choosing the right assessment method is not trivial at all.

When extending the assessment boundary to a system level covering potentially multiple nations and sub-energy systems with their supply chain properties, defining the marginal power technologies and impacts becomes virtually impossible. If electricity imports are allowed to balance supply and demand, the definition of marginal production technologies based on the technological qualities loses its basis. For example, extensive construction of wind power capacity may cause excess energy production [27], and one way to balance the supply and demand is exports. Furthermore, the other Nordic countries in the Nordic grid are net exporters of electricity while Finland is a net importer [28]. In addition, a temporal perspective to an assessment increases the complexity due to such variables as the capacity to increase renewables. In addition, even if ALCA offered relatively simple analysis options, the uncertainties of basing decision making on CLCA remain substantial. From the perspective of increasing renewable capacity, several authors have pointed out how the periodicity of both wind and solar causes problems [29-31], but there are conflicting results as to how much this actually influences the GHG emissions [30,31]. In any case, in the future, marginal power production technologies will likely be much closer to average production technologies from the perspective of GHG emissions. This leads to a situation where CLCA cannot be used based on current system dynamics as is, although it can outrank 
the ALCA approach. An adequate CLCA in this context needs to predict the development of a system within the use lifetime and/or has sensitivity and probability analyses integrated into it.

The third main problem in comparing the GHGs from CHP and other options in urban planning decision making arises from the fact that there is no unequivocal method to assign the emissions for electricity and heat in CHP production (e.g., [32]). Each one can be claimed as the primary product which should carry the main emissions load. Consequentially, a number of allocation methods have been suggested with highly varying emissions distributions. Thus, a certain CHP utility operating with purely fossil fuels can still claim to be selling very low-carbon energy. If the utility chooses to allocate the emissions mostly to electricity, which is sold to the grid with virtually no impact on the grid average, it can claim to be selling low-carbon energy due to the heat production having a low carbon content, and the electricity sold to the end-user being purchased from the grid with low average emissions. An increasing share of CHP has also been shown to relate to high variability in energy GHG assessments [33].

Under the typical CHP conditions of local CHP production and a national or even international electricity grid the one conducting an assessment or introducing a policy guideline often has the power to present the emissions in the best light for the occasion, or, as happens quite often, needs to rely on second-hand information without proper transparency. However, in the studies with an urban planning perspective, the uncertainties related to the emissions from energy production are rarely given much consideration. Therefore, the results and the policy guidelines that arise can actually rely heavily on methodological choices, but these choices may not be transparent or not even recognized at all.

The purpose of this paper is to compare, from an urban planning perspective, the choice between CHP and a ground-source heat pump (HP) as the energy systems of a new residential area in the light of the uncertainty of the GHG assessment outcomes imposed by the above-mentioned factors. In the paper we present an analysis of the GHG impact of an actual new residential development in Finland to demonstrate the complexity of such an assessment and the problems in giving robust policy guidelines for planners. With the results we show that, with different but justifiable assessment choices, a very wide array of results can be obtained leading to different planning guidelines. We also discuss the comparability of CHP and HP with different assessment assumptions. The boundary issue together with ALCA vs. CLCA is covered by comparing both average and marginal electricity with three different choices of marginal fuel.

Finland provides an interesting case for analyzing the GHG impacts of CHP penetration and comparing CHP with other energy systems. CHP already dominates the heat supply in cities [28], and high climate mitigation aspirations have been placed on urban densification policies and further CHP utilization. It has been proposed that CHP results in environmental benefits in comparison to HPs in Finnish conditions (e.g., [34]), but opinions favoring HPs have been presented as well, and there is a current debate on which of the two is in fact superior. The issue is very complex due to the fact that currently heat production in Finland relies heavily on fossil fuels [28], which leads to significant GHG emissions in absolute terms despite the benefits of CHP. At the same time, electricity in Finland is not very GHG intensive due to the high proportion of nuclear power and renewables [28]. Finland also belongs to the Nordic grid, which enjoys even lower average emissions due to the hydropower supply from Sweden and Norway. On the other hand, the current marginal production technologies are relatively GHG intensive.

The study design is introduced in Section 2. The results of the study are presented and discussed in Sections 3 and 4 gives the main conclusions. 


\section{Study Design}

\subsection{Case Setting}

This paper revisits and reanalyzes the case study of Ristimäki et al. (2013) [35] from the perspective of the GHGs from residential energy consumption. In their study Ristimäki et al. suggested that HPs would be preferable over the current CHP system from the perspectives of both the GHG and cost. However, they only used certain fixed emissions intensities and one allocation method to calculate CHP. In this paper, we reanalyzed the same case to evaluate the potential constraints and uncertainties in their study, and to see if certain assumptions would lead to the reverse selection criteria between HPs and CHP as suggested recently by Rinne and Syri (2013) [34] in a more general setting in the Finnish context.

The case area is the first phase of the new residential area of Härmälänranta in Tampere, Finland. The site is situated $5 \mathrm{~km}$ southwest from the Tampere city center and consists of 7 similar multi-story modern low-energy residential buildings. Every building has 6 floors, 28 apartments and $3100 \mathrm{~m}^{2}$, totaling overall approximately 22,000 gross $\mathrm{m}^{2}$ for around 550 residents.

The buildings of Härmälänranta fall into energy class $\mathrm{A}$ in Finland. The energy requirements estimated by Ristimäki et al. came to $80 \mathrm{kWh} / \mathrm{m}^{2} / \mathrm{a}$ for heating and hot water and $14 \mathrm{kWh} / \mathrm{m}^{2} / \mathrm{a}$ for communal building electricity [35]. For our study, we added $25 \mathrm{kWh} / \mathrm{m}^{2} / \mathrm{a}$ for household electricity based on the statistics of new district heated apartment buildings in Finland [36], for a total of approximately $2600 \mathrm{MWh} / \mathrm{a}$ for the whole case area.

The local energy company in Tampere is Tampereen Sähkölaitos Oy, which produces both heat and electricity. In the base year of the study, 2012, almost $80 \%$ of heat and $93 \%$ of electricity were produced in three CHP plants. Almost 70\% of the delivered district heat was produced by natural gas in 2012 . Other fuels used were peat (13\%), wood (17\%) and oil (2.5\%). In the study we assumed the nearest CHP plant, Naistenlahti 1, to supply the heat in CHP options. In Naistenlahti 1 only natural gas was used as a fuel in the reference year. In the future the plan of the city of Tampere is to increase the use of renewables in energy production, first to $38 \%$ in 2020 and further to $80 \%$ by 2040 . In CHP plants biogas can potentially be used instead of natural gas and solid biomass can be introduced into the DH network as well. Development scenarios from the perspective of $\mathrm{DH}$ and electricity from the grid were excluded from the study, but a discussion of the impacts of the $38 \%$ biomass future scenario is included as it represents the most likely near future change in the local production environment.

In 2012, the Finnish electricity production fuel-mix consisted of $41 \%$ renewables, $20 \%$ fossil fuels (50\% coal and 50\% natural gas), 33\% nuclear power and $6 \%$ peat [37]. $25 \%$ of the electricity came from CHP [37]. The shares fluctuate annually due to variations in the global fuel prices and in renewables production, especially due to variable weather conditions. The key case data are presented in Table 1. 
Table 1. Case Härmälänranta key numbers.

\begin{tabular}{|c|c|c|}
\hline & Categories & Values \\
\hline \multicolumn{3}{|c|}{ Härmälänranta residential area } \\
\hline- & Distance from Tampere city center $(\mathrm{km})$ & 5 \\
\hline- & DH network in close proximity & yes \\
\hline- & Space $\left(\right.$ gross $\left.\mathrm{m}^{2}\right)$ & 22,000 \\
\hline- & Apartments & 196 \\
\hline- & Estimated number of residents & 550 \\
\hline \multicolumn{3}{|c|}{ Energy consumption estimations } \\
\hline- & Heat and hot water $(\mathrm{MWh} / \mathrm{a})$ & 1730 \\
\hline- & Electricity (MWh/a) & 850 \\
\hline \multicolumn{3}{|c|}{ Naistenlahti 1 power plant } \\
\hline- & Natural gas & $100 \%$ \\
\hline \multicolumn{3}{|c|}{ Finnish electricity grid mix } \\
\hline- & Renewables & $41 \%$ \\
\hline- & Nuclear power & $33 \%$ \\
\hline- & Fossil fuels & $20 \%$ \\
\hline- & Peat & $6 \%$ \\
\hline
\end{tabular}

Finland also belongs to the Nord Pool Spot electricity market along with the other Nordic countries, Estonia and Lithuania. The Nord Pool grid is further connected to the Russian, Polish and German grids. The production profile in the Nordic countries connected to the Nord Pool Spot market is based on significantly more renewables than is Finnish electricity production. In 2012, hydropower accounted for $59 \%$, wind for $7 \%$, geothermal power for $1 \%$, nuclear for $13 \%$ and thermal power for $20 \%$ [14].

\subsection{Compared Energy Options}

We compared the two actual planning phase energy system options of Härmälänranta:

(1) CHP and

(2) HP.

We tested how the assumption on average or marginal production affects the results when different CHP allocation methods and LCA assumptions are utilized. The heating options were adopted from Ristimäki et al. [35], but also represented a current lively discussion topic in Finland. We utilized three different fuels for marginal production, coal, oil and gas (following Kara et al. 2008) [38] to give scope to the variation of the marginal mix as it should not be considered as relying on only one fuel. The marginal technology was assumed as condensing power with an efficiency range from $33 \%$ to $59 \%$ according to Cherubini et al. [23]. There is also potential temporal variation, especially over a longer time-span, in which fuel fills the final marginal demand change, although coal is dominant at the moment in Finland. Thus, an analysis with these three options provides a good overview of the impact of changes in marginal fuel use and of taking marginal production as a mix of fuels (and technologies) rather than simply as the most GHG intensive coal condensation, which is the prevailing tradition in Finland. Table 2 presents the compared options. 
Table 2. Compared energy options.

\begin{tabular}{|c|c|c|c|c|c|c|c|c|}
\hline \multirow{2}{*}{$\begin{array}{c}\text { Option } \\
\begin{array}{c}\text { Allocation/ } \\
\text { fuel }\end{array}\end{array}$} & \multicolumn{2}{|c|}{$\begin{array}{c}\text { CHP with } C H P \\
\text { Electricity }\end{array}$} & \multicolumn{3}{|c|}{$\begin{array}{c}\text { HP with Marginal } \\
\text { Electricity }\end{array}$} & \multicolumn{3}{|c|}{$\begin{array}{l}\text { Grid Average } \\
\text { Electricity }\end{array}$} \\
\hline & $\begin{array}{l}\text { Benefit } \\
\text { Method }\end{array}$ & $\begin{array}{l}\text { Energy } \\
\text { Method }\end{array}$ & Coal & Oil & Gas & $\begin{array}{l}\text { Benefit } \\
\text { Method }\end{array}$ & $\begin{array}{l}\text { Energy } \\
\text { Method }\end{array}$ & HP \\
\hline Description & $\begin{array}{l}\text { CHP hea } \\
\text { and the r } \\
\text { electricit } \\
\text { producti } \\
\text { allocatec } \\
\text { settleme } \\
\text { their ele } \\
\text { demand. }\end{array}$ & $\begin{array}{l}\text { is used } \\
\text { sulting } \\
\text { is } \\
o \text { the } \\
\text { up to } \\
\text { icity }\end{array}$ & $\begin{array}{l}\text { Coal as a } \\
\text { marginal } \\
\text { fuel } \\
\text { providing } \\
\text { all the } \\
\text { electricity } \\
\text { needed. }\end{array}$ & $\begin{array}{l}\text { Oil as a } \\
\text { marginal } \\
\text { fuel } \\
\text { providing } \\
\text { all the } \\
\text { electricity } \\
\text { needed. }\end{array}$ & $\begin{array}{l}\text { Gas as a } \\
\text { marginal } \\
\text { fuel } \\
\text { providing } \\
\text { all the } \\
\text { electricity } \\
\text { needed. }\end{array}$ & $\begin{array}{l}\text { CHP heat } \\
\text { but electri } \\
\text { assumed } t \\
\text { from the } \mathrm{r} \\
\text { grid. }\end{array}$ & $\begin{array}{l}\text { used } \\
\text { ity is } \\
\text { come } \\
\text { nnish }\end{array}$ & $\begin{array}{l}\text { HP provides } \\
\text { heat operating } \\
\text { with grid } \\
\text { average } \\
\text { electricity. } \\
\text { Housing } \\
\text { electricity is also } \\
\text { grid average. }\end{array}$ \\
\hline
\end{tabular}

CHP is assumed to have a production efficiency range of $80 \%$ to $95 \%$ (HHV; higher heating value) following Cherubini et al. [23], of which $30 \%-45 \%$ is electricity and $50 \%$ heat. Transmission losses are excluded and are expected to be equal between electricity and heat. We also assumed $60 \%$ of the peak power demand to be produced by the CHP plant and the rest in a peak heating plant, resulting in approximately $20 \%$ of the DH demand to come from heating plants. For the heating plants we utilized an efficiency range of $77 \%$ to $91 \%$ from Cherubini et al. [23]. In the assessment the CHP fuel-mix is $100 \%$ natural gas, and the peak heating plant is assumed to operate with natural gas as well.

The "CHP with CHP electricity"-option is not very often included in any assessments, but we see it as a very relevant option due to the fact that the increase in the heat demand also drives increased electricity production. Commonly heat production from a CHP plant enables and drives the electricity production of such a plant, but not the other way around. As the heat demand of a site has a subsequent impact on the electricity production of the CHP plant involved, the electricity should as well be allocated to the site responsible for the increased production, at least up to the demand level. Furthermore, later in the paper we discuss the very general phenomenon that with certain CHP allocation methods a utility can claim to sell both very low carbon heat and very low carbon electricity even though it actually operates with fossil fuels with relatively high carbon contents.

Assessing the electricity demand of the CHP areas with CHP electricity enables depicting better the full subsequent impact of the new development. In our case, the subsequent change in the local CHP plant's electricity output is relatively close to the site's annual demand. Although the match is weaker if the daily and seasonal fluctuations were taken into account, this option depicts an important perspective. If there were surplus electricity from the residential area and CHP, it would decrease the marginal electricity production of the system and thus would have a reduction impact on the emissions from the current system. If the development of electricity and marginal technology production were to lead to marginal electricity production with lower emissions than the surplus electricity from the CHP, emissions would naturally increase. Ultimately the case is about subsequent displacement of resources and a precise assessment of the GHG impact of the new settlement would be very complex. Notwithstanding, the suggested "CHP with CHP electricity" option allows for assessing the GHGs when the grid impact is unknown. It is also worth noting that the "CHP with CHP electricity" option can be justified as today 
the plants are driven by the level of demand for heat. If there were true excess heat available from, for instance, a power plant driven by the demand for electricity, the allocation option would not be relevant.

Regarding the HP options, the efficiency measure of HPs, COP (Coefficient of Performance), i.e., the ratio of produced heat to required electricity to run the pump, is typically 2.6-3.6 [39], and here we used 3.0, following Ristimäki et al. [35]. COP can actually reach a level of over 4.0 (e.g., [34,40]), and we discuss the impact of the COP assumption on the results as well. HPs are typically not fitted to provide $100 \%$ of the needed heat due to decreasing overall efficiency, and at least during peak hours electric heating resistors are used as complementary heaters [41], but the COP figure takes this into account.

\subsection{Life Cycle GHG Intensities for Different Fuels}

The published GHG intensities for different fuels and production modes vary significantly depending on the source, for example because of the assessment boundary definition and several necessary assumptions (e.g., [23,25]). Cherubini et al. (2009) [23] present ranges based on published LCAs for different fuels and production modes for electricity and cogeneration, which we employed in our study. The ranges do not necessarily present the highest or the lowest values suggested by earlier studies, but a wide enough spread to have a significant impact on the results and thus demonstrate the importance of the intensity assumptions. The intensities are for the output, thus including also the conversion efficiency as an important factor. Table 3 presents the figures from Cherubini et al. [23] employed in this study.

Table 3. GHG intensities for certain electricity and cogeneration technologies and fuels from Cherubini et al. (2009) [23].

\begin{tabular}{cc}
\hline Fuel/Production Mode & $\mathbf{g ~ C O}_{\mathbf{2}} \mathbf{e} / \mathbf{k W h}$ \\
\hline Biomass & $54 \ldots 108$ \\
Biogas & $54 \ldots 234$ \\
Wind & $3.6 \ldots 36$ \\
Geothermal & $7.2 \ldots 36$ \\
Hydro & $1.8 \ldots 36$ \\
Solar & $54 \ldots 144$ \\
Coal & $1080 \ldots 1800$ \\
Oil & $720 \ldots 1080$ \\
Nuclear & $18 \ldots 108$ \\
Natural gas & $360 \ldots 720$ \\
\hline
\end{tabular}

Using the production distribution of the Finnish grid (see Section 2.1.) and the lower and upper values of Table 3 for calculating, the Finnish electricity production intensity has a lower boundary of $213 \mathrm{~g} \mathrm{CO}_{2} \mathrm{e} / \mathrm{kWh}$ and an upper boundary of $391 \mathrm{~g} \mathrm{CO}_{2} \mathrm{e} / \mathrm{kWh}$.

For the CHP gas power plant the intensity boundaries are the range for natural gas, and for marginal production we used the ranges for coal, oil and natural gas in Table 3. For the separate heat production in peak heating plants we used the range of $252 \ldots 306 \mathrm{~g} \mathrm{CO}_{2} \mathrm{e} / \mathrm{kWh}$ for natural gas retrieved from the same study of Cherubini et al. (2009) [23] for separate heat production. Other fuels could be used as well to fulfill the peak heat demand, but the impact of separate production in our case is low. 


\subsection{Emissions Allocation Methods in Co-Production}

There are a number of different calculation methods for allocating CHP plant emissions. These include the benefit method, energy method, the energy method, all-for-heat/electricity method, product price method, EN 15316-4-5: 2007 standard's method, ratio method, and work method. Different methods can lead to very different outcomes with important impacts on the assessment results.

In this study, the two most relevant methods were used in the calculations to allow comparisons between them:

(1) benefit method as the dominant method used in Finland and

(2) energy method as the globally most widely used method.

In addition, the all-for-electricity method was used to demonstrate an extreme case possible with the different allocation methods.

In the benefit method the emissions of a CHP plant are divided according to the ratio of fuel consumption of separate production forms. For electricity the alternative production form is a condensing power plant (efficiency 33\%-59\%) and for a thermal water boiler (efficiency $77 \%-91 \%$ ). Efficiency ranges, according Cherubini et al. (2009) [23] representing true alternative conversion efficiencies, were utilized in the minimum and maximum calculations. Consequently, in this method, the weighting is based on the efficiencies of the separate energy productions of heat and electricity, and it makes a good comparison of the combined production's benefits if heat and electricity are produced separately. The benefit is allocated to both end fractions. In the calculation, first the fuel consumption of alternative acquisition forms is calculated by dividing the produced energy form in cogeneration by the efficiency of the separate production of energy form.

$$
\begin{aligned}
\boldsymbol{F}^{\prime}{ }_{\boldsymbol{e}} & =\frac{\boldsymbol{E}_{\boldsymbol{e}}}{\boldsymbol{\eta}_{\boldsymbol{e}}} \\
\boldsymbol{F}_{\boldsymbol{h}}^{\prime} & =\frac{\boldsymbol{E}_{\boldsymbol{h}}}{\boldsymbol{\eta}_{\boldsymbol{h}}}
\end{aligned}
$$

where

$F^{\prime}{ }^{\text {e }}=$ fuel consumption of alternative acquisition form for electricity

$F^{\prime}{ }^{h}=$ fuel consumption of alternative acquisition form for heat

$E_{\mathrm{e}}=$ produced electricity in cogeneration

$E_{\mathrm{h}}=$ produced heat in cogeneration

$\eta_{\mathrm{e}}=$ efficiency of separate production of electricity $(33 \%-59 \%)$

$\eta_{\mathrm{h}}=$ efficiency of separate production of heat $(77 \%-91 \%)$

The actual fuel consumption allocated to an end energy fraction is calculated with the ratio of the primary energy used to produce it with the separate energy production and the primary energy needed to produce both the energy fraction with the separate production forms.

$$
F_{e}=F \frac{F_{e}^{\prime}}{F_{e}^{\prime}+F_{h}^{\prime}}
$$




$$
\boldsymbol{F}_{\boldsymbol{h}}=\boldsymbol{F} \frac{\boldsymbol{F}_{\boldsymbol{h}}^{\prime}}{\boldsymbol{F}_{\boldsymbol{e}}^{\prime}+\boldsymbol{F}_{\boldsymbol{h}}^{\prime}}
$$

where,

$F_{\mathrm{e}}=$ calculated fuel consumption of electricity production in cogeneration

$F_{\mathrm{h}}=$ calculated fuel consumption of heat production in cogeneration

$F=$ consumption of fuel in cogeneration

In the energy method, the emissions are divided according to the ratio of produced final energy fractions. This method addresses extra emissions of heat in comparison with separate production, because the efficiency of separate heat production is higher than the efficiency in cogeneration. The division of emissions is calculated by dividing the fuel consumption of energy by the total fuel consumption and multiplying by the fuel consumption of cogeneration.

$$
\begin{aligned}
& F_{e}=F \frac{E_{e}}{E_{e}+E_{h}} \\
& F_{h}=F \frac{E_{h}}{E_{e}+E_{h}}
\end{aligned}
$$

In the all-for-electricity method fuels are primarily subjected to electricity. Primary energy demand for electricity is calculated given the assumption that the electricity is generated via separate condensing power production. The fuel consumption of alternative electricity production is calculated by dividing the produced electricity in cogeneration by the efficiency of the separate production of electricity.

$$
F_{e}=\frac{E_{e}}{\eta_{e}}
$$

The primary energy allocated to heat is calculated by the difference between the total primary energy used for CHP and the primary energy allocated to electricity.

$$
\boldsymbol{F}_{\boldsymbol{h}}=\boldsymbol{F}-\boldsymbol{F}_{\boldsymbol{e}}
$$

\section{Results and Discussion}

\subsection{Assessment Results of Härmälänranta}

With different assessment choices and assumptions the annual GHG impact of the Härmälänranta settlement fall into a range of $290 \mathrm{t} \mathrm{CO}_{2} \mathrm{e} / \mathrm{a}$ to $2530 \mathrm{t} \mathrm{CO} 2 \mathrm{e} / \mathrm{a}$, the assessment thus entailing a huge uncertainty. Furthermore, both the highest and the lowest are HP options with different LCA and electricity production assumptions. In between the extremes, CHP options vary less but still significantly enough to affect any decision guidelines. The results thus depict very clearly how difficult the energy assessment situation is from the perspective of urban planning.

In Figure 1a the results of the different options are presented according to the lower GHG intensity boundaries (see Section 2.4.). Figure $1 \mathrm{~b}$ presents the results according to the higher boundaries. The policy guideline seems therefore to be that HP should be favored if the average grid electricity assumption is utilized, but if marginal production is assumed, HP is a better option only if marginal production is assumed to consist of a mix including a significant share of natural gas based condensation 
power with high conversion efficiency (or imported low-intensity electricity). In the following subsections, the main issues are discussed, which hinder robust policy guidelines regarding energy system choices in urban planning.

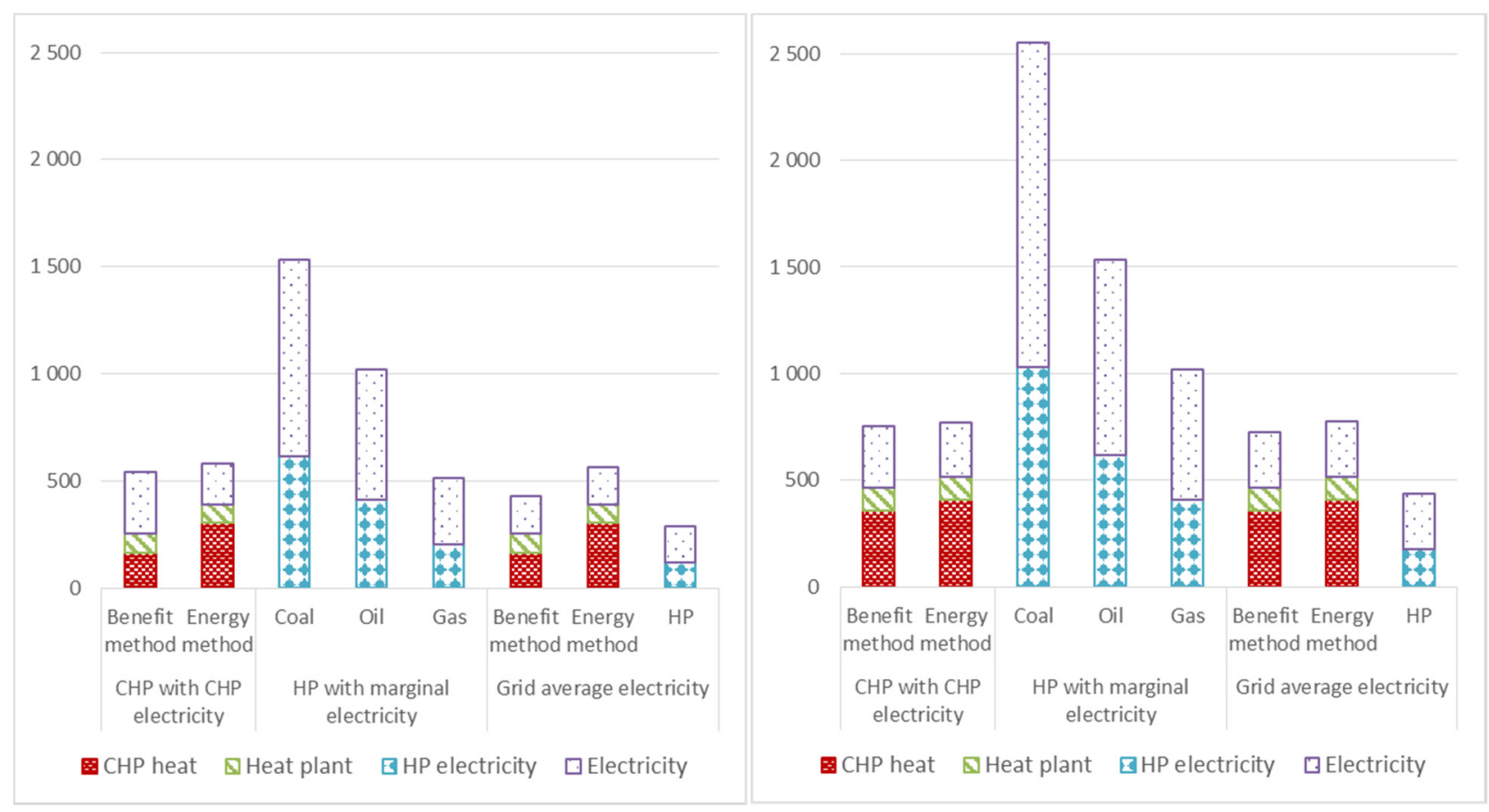

(a)

(b)

Figure 1. (a) The annual GHGs incurred by the Härmälänranta settlement with the lower GHG intensity boundaries ( $\mathrm{t} \mathrm{CO}_{2} \mathrm{e} / \mathrm{a}$ ); (b) The annual GHGs incurred by the Härmälänranta settlement with the upper GHG intensity boundaries ( $\left.\mathrm{t} \mathrm{CO}_{2} \mathrm{e} / \mathrm{a}\right)$.

\subsection{Interpretation of Results and Discussion}

\subsubsection{Average and Marginal Electricity}

First, and perhaps most importantly, the very uncertain assumption about utilizing marginal or average electricity in the assessment can turn the results upside down. Especially with flexible smart electricity grids in the future and electricity trade filling the demand peaks, average grid electricity can be a justified option in an assessment like this. However, these are predictions rather than facts, and thus it is of importance to understand the uncertainties when decisions are made.

As depicted in Figure 1a,b, HP with average electricity is the best option, varying between 290 t CO $2 \mathrm{e} / \mathrm{a}$ and 440 t CO $2 \mathrm{e} / \mathrm{a}$ for the Härmälänranta area depending on the GHG intensities. Even with the benefit method, which allocates the majority of the emissions to electricity, and with average electricity from the grid, CHP leads to significantly higher emissions. Furthermore, since the benefit method allocates the majority of the emissions to electricity, the consequential emissions from the CHP utilization in Härmälänranta would be much higher. This issue is discussed further in Section 3.2.2.

With the marginal electricity assumption a very important decision is which fuel and technology is selected to describe the marginal production. In Finland it has traditionally been coal condensing, which leads to by far the highest emissions in our assessment and gives a clear preference to CHP. However, 
the global market prices of fuels define the fuel utilization in the long run. Furthermore, electricity imports and the wide interest in eliminating coal as a fuel completely can significantly reduce the role of condensing coal plants as a marginal technology. Thus, the marginal options of oil and natural gas can also depict the impact of an increase in electricity demand in the case where Finnish marginal production only partially fills the demand gap.

As shown in Figure $1 \mathrm{a}, \mathrm{b}$, for oil as the marginal fuel the range in our assessment is $1020 \ldots 1530 \mathrm{t} \mathrm{CO}_{2} \mathrm{e} / \mathrm{a}$, which is already well above the CHP options. For natural gas the range is $510 \ldots 1020 \mathrm{t} \mathrm{CO}_{2} \mathrm{e} / \mathrm{a}$. This is the most interesting of the marginal options, since with the lower GHG intensity boundary HP becomes preferable to CHP in our case, but with the higher GHG boundaries the preference order is the opposite. Thus, it seems that when moving towards high efficiency gas condensation as the marginal technology, HP option becomes competitive even when HPs are assumed to push marginal production, but the exact preference order in a certain case requires detailed information about the local production conditions.

\subsubsection{CHP Allocation Methods}

The second problem arises from the CHP allocation methods and the electricity assumption in the CHP options. CHP can be made to seem as good an option with HP even with the average electricity assumption, if a large enough share of the GHGs from CHP is allocated to electricity. Such a method is, for example, the all-for-electricity method (see Section 2.4.). With the all-for-electricity method CHP heat with average grid electricity would lead to a range from $260 \mathrm{t} \mathrm{CO}_{2} \mathrm{e} / \mathrm{a}$ to $640 \mathrm{t} \mathrm{CO} 2 \mathrm{e} / \mathrm{a}$ for Härmälänranta, thus highlighting the possibility to color the outcome of the analysis.

Nevertheless, the heat demand also drives the CHP electricity output. The all-for-electricity method with average grid electricity thus gives a very biased image of the actual emissions caused by the new settlement. Assigning the electricity-related emissions for the settlement based on CHP electricity thus gives very different results. The range would run from 490 t $\mathrm{CO}_{2} \mathrm{e} / \mathrm{a}$ to $730 \mathrm{t} \mathrm{CO}_{2} \mathrm{e} / \mathrm{a}$ depending on the fuel intensities adopted, which is virtually equal to the other CHP options with CHP electricity.

With regard to the main methods utilized in this study, the benefit method and the energy method, the differences are less extreme than with the all-for-electricity method, as Figure 1a,b show. However, comparisons of CHP with average electricity and HP with marginal electricity are not well justified overall. If HPs are assumed to drive marginal production, CHP clients should be allocated the emissions from CHP electricity as well when comparing the consequential impacts of HP and CHP as the energy solutions of a new settlement. With different fuel-mixes this issue can potentially be of much higher importance.

\subsubsection{GHG Intensities of Different Fuels/Production Modes}

The third issue is that the variation in the results is huge just in terms of the selected GHG intensities (including the conversion efficiency) for different fuels and production types (between Figure 1a,b), which should be only background information in the planning context. Differences of this magnitude significantly affect the importance of the energy system choice in comparison with other means to affect the emissions caused by a certain settlement and thus make robust decisions very problematic. 
In addition, the ranges presented by Cherubini et al. (2009) [23], and utilized in this study, are by no means absolute highs/lows. Especially regarding biomass the situation is very difficult since the temporal perspective plays a major role (e.g., $[42,43])$. Biomass is often taken as a very low carbon option, and in Tampere as well as in Finland in general strong expectations are placed on the potential of biomass to decrease the emissions from CHP and separate heat production in the future. With the GHG intensity range of Cherubini et al. (2009) [23] for biomass, 54...108 g CO $2 \mathrm{e} / \mathrm{kWh}$, the $38 \%$ biomass scenario for the City of Tampere (see Section 2.2.) would reduce the GHGs caused by Härmälänranta by approximately $10 \%$ to $20 \%$ compared to the current situation. However, biomass, especially in the form of northern forests, is actually low GHG fuel only in the very long run, when the forest stocks are recovered (e.g., [42-44]). Thus, the GWP100 factors utilized might not be appropriate for assessing the impacts of biomass utilization. For example, Cherubini et al. (2012) [44] assess the GWP20 factor for northern forest utilization as biomass in energy production as falling approximately in the range of $400 \ldots 600 \mathrm{~g} / \mathrm{kWh}$. The $38 \%$ biomass scenario could thus actually increase the emissions from the current (natural gas comparison) in the short term and only after decades improve the balance.

The timing issue has not yet been given the attention it deserves, but similar examples have been presented regarding biofuel production [45] and construction and buildings [46]. Especially since the GHG mitigation targets have been set to the relatively near future, this perspective should be given more consideration. The issue is highly complex, however. For example, if the timber were to be used for something else and only the residues used as fuel, the assessment setting would change substantially. In addition, higher demand for residues could lead to increased utilization of wood products as a whole and thus potentially increase the total volume of the natural carbon stock. Only understanding the complex overall consequential impacts would allow determining the sustainability of alternative courses of action.

\subsection{Additional Perspectives}

\subsubsection{Relationship between CHP and Marginal Electricity Production}

An often utilized argument favoring CHP is that connecting a new settlement to CHP in theory replaces the need for marginal production, assuming that the other options are direct electricity or HPs, and that they drive marginal production. Regarding a specific urban planning situation, however, evaluating this potential substitution effect is very complex. Only a fraction, if any, of the energy demand of a new settlement is actually new demand, the rest being just relocated demand. Demand at some local energy system level may be eliminated and new demand generated at the new site with potential consequential impacts, but these are virtually impossible to estimate at the planning stage. In any case the potential substitution effect is of limited scale.

In addition, if electricity from a CHP plant is seen to substitute hypothetical marginal electricity, the GHGs caused by electricity consumption at the settlement in question need to be calculated based on CHP electricity, since that is the consequential GHG load and the alternative to marginal production. The gain would thus be the difference between the emissions from the hypothetical marginal production and those from CHP. Furthermore, marginal production is not present only in grid electricity. In addition, CHP and other single plants, as well as whole district heating systems, can be operated with multiple fuels and so the marginal potential is present also within CHP and DH systems. In this study, we assumed 
natural gas as the only CHP fuel, but much higher intensity fuels could as well be assumed as marginal fuels for a specific plant. Thus, when true consequential impacts are analyzed, the actual fuel should be taken into account as well.

Finally, extending the assessment boundary to include imports leads to a situation where the so-called marginal demand can be met with imported electricity as well as with local or national production, which in the Finnish case is often very low-intensity Nordic hydropower. The future smart grids will also reduce the need for today's marginal production. Together with increasing renewables-based production capacity in Finland, the fossil fuels utilization is likely to decrease and less and less of such marginal production as described in this study will be needed. CHP electricity might thus become the production option with the highest GHG intensity.

\subsubsection{The Impact of COP}

Regarding HP technologies, we utilized a COP of 3.0 throughout the assessments. However, even currently the COP can be as high as over four (e.g., [34,40]) and in the future will presumably rise even higher. We ran the same analysis with COP 4.0 as well, but the resulting GHG reduction of $10 \%$ did not significantly affect the decision guidelines in the case of Härmälänranta. The HP with marginal coal or oil options remained as the worst options and HP with marginal gas option with the lower emissions intensities boundary, but with the upper boundary CHP remains as the preferable option even with a COP of as high as 5.0. However, in another situation with the local CHP plant operating for example with coal and peat (a viable option in Finland), this increase in COP would quickly increase the competitiveness of HP. The lower boundary of 2.6 (see Section 2.3.) would not significantly affect the results either.

\section{Conclusions}

This study was set to analyze how energy systems should be viewed in environmentally aware urban planning and related decision making. The choice of energy system is often the most important factor in the GHG emissions of a residential area and should thus have a very central role in the environmental considerations of urban planning. CHP has a strong push globally due to its potential to reduce the GHGs compared to separate heat and electricity production (e.g., $[9,10])$. However, the uncertainties in assessing the emissions from $\mathrm{CHP}$ and alternative options related to any specific planning situation make it very difficult to give any robust guidelines for planning. Consequently, the assessments are inevitably based on strong general assumptions instead of including the local conditions, leading potentially to biased results and unwanted GHG development in the long run. In addition to the difficulties in rating the order of preference to different energy production modes, even the order of magnitude for the emissions caused by a certain settlement is difficult to assess robustly due to the uncertainties related to the GHG intensities of different production modes, fuels and grid averages (discussed in detail e.g., in [23,25,47]).

In the study we analyzed the new residential development of Härmälänranta in Tampere, Finland, which had earlier been studied by Ristimäki et al. (2013) [35], who concluded that HPs should be preferred over CHP as the energy system from the perspective of GHGs. On the other hand, Rinne and Syri (2013) [34] have recently suggested just the opposite order of preference in Finnish conditions. Our results show clearly how strongly assumption-dependent any preference order actually is. We presented several very problematic issues which hinder robust decisions in any such assessment with regard to the 
GHG outcome. According to our results, either option can be the preferable one in a certain operating environment, and it is actually often a very complex task to determine the preference order.

In general we suggest in this paper an assessment method in which the CHP electricity is first allocated to those demanding the heat and only the possibly remaining share is fed to the grid. This has not been the dominant method, but the justifications are clear in the context of our study: CHP electricity output follows heat production, the same sources of demand thus holding certain responsibility for electricity production as well, according to the consumer responsibility principle (e.g., [48]). Furthermore, this allocation allows a more balanced comparison between CHP and HP, since the different allocation methods have less impact on the overall emissions, as depicted in Figure 1. CHP heat clients cannot be assumed to drive marginal electricity production with their demand unless it exceeds the CHP electricity output (at a certain point of time). However, it is not fully justified to assess the electricity demand of CHP clients with a grid average, especially if HPs are assumed to drive marginal production.

The context of the study was Finland, specifically an area of Tampere, but the issue observed and the results achieved have wider relevance. Wherever heat is produced locally and electricity is provided by at least a regional grid, similar complexities are likely to occur in GHG assessments. For example, in other Nordic countries the issue is highly topical (e.g., $[33,49])$. Furthermore, given that CHP production is seen as a potential means to significantly help in stabilizing the global GHGs, the related complexity in GHG assessments should be better understood. For a full picture, the study should also be extended to cover the exergy perspective as well as different fuel-mixes for the CHP plant.

\section{Acknowledgments}

We thank the Academy of Finland (Grant 286747) and Tekes - the Finnish Funding Agency for Innovation (Project 984/12) for enabling the study.

\section{Author Contributions}

The first author conducted the assessments and wrote the main part of the paper. The second author participated in the research design and the assessments, collected background data and helped write parts of the paper. The third author collected data, conducted the initial calculations and helped write parts of the paper. The fourth, fifth and sixth authors were consulted about the research design and commented on the manuscript during the writing process.

\section{Conflicts of Interest}

The authors declare no conflict of interest.

\section{References}

1. IPCC. IPCC Special Report on Renewable Energy Sources and Climate Change Mitigation. Prepared by Working Group III of the Intergovernmental Panel on Climate Change; Edenhofer, O., Pichs-Madruga, R., Sokona, Y., Seyboth, K., Matschoss, P., Kadner, S., Zwickel, T., Eickemeier, P., Hansen, G., Schlömer, S., et al. Eds.; Cambridge University Press: Cambridge, UK; New York, NY, USA, 2011; p. 1075. 
2. IEA (The International Energy Agency). World Energy Outlook 2008; OECD/IEA: Paris, France, 2008; p. 569.

3. Hoornweg, D.; Sugar, L.; Trejos Gomez, C. Cities and greenhouse gas emissions: Moving forward. Environ. Urban. 2011, 23, 207-227.

4. United Nations. City Planning Will Determine Pace of Global Warming; UN Sixty-Second General Assembly, Second Committee; United Nations: New York, NY, USA, 2007.

5. Kenworthy, J.R. The eco-city: Ten key transport and planning dimensions for sustainable city development. Environ. Urban. 2006, 18, 67-85.

6. Glaeser, E.; Kahn, M. The greenness of cities: Carbon dioxide emissions and urban development. J. Urban Econ. 2010, 67, 404-418.

7. Seto, K.C.S.; Dhakal, A.; Bigio, H.; Blanco, G.C.; Delgado, D.; Dewar, L.; Huang, A.; Inaba, A.; Kansal, S.; Lwasa, J.E.; et al. Human Settlements, Infrastructure and Spatial Planning. In Climate Change 2014: Mitigation of Climate Change; Contribution of Working Group III to the Fifth Assessment Report of the Intergovernmental Panel on Climate Change; Edenhofer, O., Pichs-Madruga, R., Sokona, Y., Farahani, E., Kadner, S., Seyboth, K., Adler, A., Baum, I., Brunner, S., Eickemeier, P., et al. Eds.; Cambridge University Press: Cambridge, UK; New York, NY, USA, 2014.

8. Säynäjoki, E.; Heinonen, J.; Junnila, S. The Power of Urban Planning on Environmental Sustainability: A Focus Group Study in Finland. Sustainability 2014, 6, 6622-6643.

9. IEA (The International Energy Agency). Combined Heat and Power: Evaluating the Benefits of Greater Global Investment; OECD/IEA: Paris, France, 2008; p. 39.

10. IEA (The International Energy Agency). Global CHP/DHC Data-Current Baseline [referred: 26.2.2015]. Available online: http://www.iea.org/chp/data/globalchpdhcdata-currentbaseline/ (accessed on 26 August 2015).

11. Berta, G.; Prato, A.; Garbarino, L. Design criteria for distributed cogeneration plants. Energy 2006, $31,1403-1416$.

12. Rajala, P.; Hirvonen, H.; Perttula, S.; Lähde, E.; Pulkka, P.; Jarmala, L.; Laukkanen, J.; Patronen, J.; Jokinen M.; Rintala, T.; et al. Energiatehokkuus Kaavoituksessa; Sitran selvityksiä 41; Sitra: Helsinki, Finland, 2010.

13. Lund, H.; Andersen A.N. Optimal designs of small CHP plants in a market with fluctuating electricity prices. Energy Convers. Manag. 2005, 46, 893-904.

14. IEA (The International Energy Agency). Energy Policies of IEA Countries; Germany, 2013 Review; OECD/IEA: Paris, France, 2013; p. 212.

15. Säynäjoki, E.; Heinonen, J.; Junnila, S. Role of Urban Planning in Encouraging More Sustainable Lifestyles. J. Urban Plan. Dev. 2014, 141, 04014011.

16. Heinonen, J.; Junnila, S. Residential energy consumption patterns and the overall housing energy requirements of urban and rural households in Finland. Energy Build. 2014, 76, 295-303.

17. Neuman, M. The Compact City Fallacy. J. Plan. Educ. Res. 2005, 25, 11-26.

18. Holden, E.; Norland, I. Three Challenges for the Compact City as a Sustainable Urban Form: Household Consumption of Energy and Transport in Eight Residential Areas in the Greater Oslo Region. Urban Stud. 2005, 42, 2145-2166.

19. Björklund, A. Survey of Approaches to Improve Reliability in LCA. Int. J. Life Cycle Assess. 2002, 7, 64-72. 
20. McCarthy, R.; Yang, C. Determining marginal electricity for near-term plug-in and fuel cell vehicle demands in California: Impacts on vehicle greenhouse gas emissions. J. Power Sources 2010, 195, 2099-2109.

21. Mathiesen, B.; Münster, M.; Fruergaard, T. Uncertainties related to the identification of the marginal energy technology in consequential life cycle assessments. J. Clean. Product. 2009, 17, 1331-1338.

22. Lund, H.; Mathiesen, B.; Christensen, P.; Schmidt, J. Energy system analysis of marginal electricity supply in consequential LCA. Int. J. Life Cycle Assess. 2010, 15, 260-271.

23. Cherubini, F.; Birda, N.; Cowie, A.; Jungmeier, G.; Schlamadinger, B.; Woess-Gallasch, S. Energy- and greenhouse gas-based LCA of biofuel and bioenergy systems: Key issues, ranges and recommendations. Resourc. Conserv. Recycl. 2009, 53, 434- 447.

24. Curran, M.; Mann, M.; Norris, G. The international workshop on electricity data for life cycle inventories. J. Clean. Product. 2005, 13, 853-862.

25. Soimakallio, S.; Kiviluoma, J.; Saikku, L. The complexity and challenges of determining GHG (greenhouse gas) emissions from grid electricity consumption and conservation in LCA (life cycle assessment)_A methodological review. Energy 2011, 36, 6705-6713.

26. Plevin, R.; Delucchi, M.; Creutzig, F. Using Attributional Life Cycle Assessment to Estimate Climate-Change Mitigation Benefits Misleads Policy Makers. J. Ind. Ecol. 2013, 18, 73-83.

27. Lund, H. Renewable energy strategies for sustainable development. Energy 2007, 32, 912-919.

28. IEA (The International Energy Agency). Nordic Energy Technology Perspectives-Pathways to a Carbon Neutral Energy Future; OECD/IEA: Paris, France, 2012; p. 211.

29. Ipakchi, A.; Albuyel, F. Grid of the Future. Are We Ready to Transition to a Smart Grid? IEEE Power Energy Mag. 2009, 52-64, doi:10.1109/MPE.2008.931384.

30. Lew, D.; Brinkman, G.; Ibanez, E.; Florita, A.; Heaney, M.; Hodge, B.-M.; Hummon, M.; Stark, G.; King, J.; Lefton, S.A.; et al. The Western Wind and Solar Integration Study Phase 2: National Renewable Energy Laboratory; Technical Report NREL/TP-5500-55588; NREL: Denver, CO, USA, 2013; p. 244.

31. Katzenstein, W.; Apt, J. Air emissions due to wind and solar power. Environ. Sci. Technol. 2009, 43, 253-258.

32. Frischknecht, R. Allocation in Life Cycle Inventory Analysis for Joint Production. Int. J. Life Cycle Assess. 2000, 5, 85-95.

33. Soimakallio, S.; Saikku, L. $\mathrm{CO}_{2}$ emissions attributed to annual average electricity consumption in OECD (Organization for Economic Co-operation and Development). Energy 2012, 38, 13-20.

34. Rinne, S.; Syri, S. Heat pump versus combined heat and power production as $\mathrm{CO}_{2}$ measures in Finland. Energy 2013, 57, 308-318.

35. Ristimäki, M.; Säynäjoki, A.; Heinonen, J.; Junnila, S. Combining life cycle costing and life cycle assessment for an analysis of a new residential district energy system design. Energy 2013, 63, $168-179$.

36. Statistics Finland Official Statistics of Finland (OSF): Households' Consumption [e-publication]. ISSN=2323-3028. Helsinki: Statistics Finland. Available online: http://stat.fi/til/ktutk/tau_en.html (accessed on 12 February 2015). 
37. Statistics Finland Official Statistics of Finland (OSF): Energiavuosi 2012 (Energy year 2012), [e-publication]. ISSN=1796-0479. Helsinki: Statistics Finland. Available online: http://pxweb2.stat.fi/sahkoiset_julkaisut/energia2013/html/suom0016.htm (accessed on 12 February 2015).

38. Kara, M.; Syri, S.; Lehtilä, A.; Helynen, S.; Kekkonen, V.; Ruska, M.; Forsström, J. The impacts of $\mathrm{EU} \mathrm{CO}_{2}$ emissions trading on electricity markets and electricity consumers in Finland. Energy Econ. 2008, 30, 193-211.

39. Vartiainen, E.; Luoma, P.; Hiltunen, J.; Vanhanen, J. Hajautettu Energiantuotanto: Teknologia, Polttoaineet Markkinat ja CO2-Päästöt; Gaia Group Oy: Helsinki, Finland, 2002; p. 90.

40. Kuronen, M.; Junnila, S.; Majamaa, W.; Niiranen, I. Public-private-people partnership as a way to reduce carbon dioxide emissions from residential development. Int. J. Strategic Property Manag. 2010, 14, 200-216.

41. Nystedt, Å.; Sepponen, M.; Virtanen, M. Ekotaajaman Suunnitteluperiaatteet; VTT: Espoo, Finland, 2012.

42. Cherubini, F.; Peters, G.; Berntsen, T.; Strømman, A.; Hertwich, E. $\mathrm{CO}_{2}$ emissions from biomass combustion for bioenergy: atmospheric decay and contribution to global warming. GCB Bioenergy 2011, 3, 413-426.

43. Helin, T.; Sokka, L.; Soimakallio, S.; Pingoud, K.; Pajula, T. Approaches for inclusion of forest carbon cycle in life cycle assessment-A review. GCB Bioenergy 2013, 5, 475-486.

44. Cherubini, F.; Bright, R.; Strømman, A. Site-specific global warming potentials of biogenic $\mathrm{CO}_{2}$ for bioenergy: Contributions from carbon fluxes and albedo dynamics. Environ. Res. Lett. 2012, 7, 045902.

45. Schwietzke, S.; Griffin, W.; Matthews, H. Relevance of emissions timing in biofuel greenhouse gases and climate impacts. Environ. Sci. Technol. 2011, 45, 8197-8203.

46. Säynäjoki, A.; Heinonen, J.; Junnila, S. A scenario analysis of the life cycle greenhouse gas emissions of a new residential area. Environ. Res. Lett. 2012, 7, 034037.

47. Blum, P.; Campillo, G.; Münch, W.; Kölbel, T. $\mathrm{CO}_{2}$ savings of ground source heat pump systems-A regional analysis. Renew. Energy 2010, 35, 122-127.

48. Lenzen, M.; Murray, J.; Sack, F.; Wiedmann, T. Shared producer and consumer responsibility-Theory and practice. Ecol. Econ. 2007, 61, 27-42.

49. Slagstad, H.; Brattebø, H. Use of LCA to evaluate solutions for water and waste infrastructure in the early planning phase of carbon-neutral urban settlements. Smart Sustain. Built Environ. 2013, $2,28-42$.

(C) 2015 by the authors; licensee MDPI, Basel, Switzerland. This article is an open access article distributed under the terms and conditions of the Creative Commons Attribution license (http://creativecommons.org/licenses/by/4.0/). 